\title{
ISR Phenikaa Uni vươn lên \#3 bảng RePEc 2020
}

\author{
Nguyễn Thanh Huyền \\ Trung tâm ISR \\ Trường Đại học Phenikaa

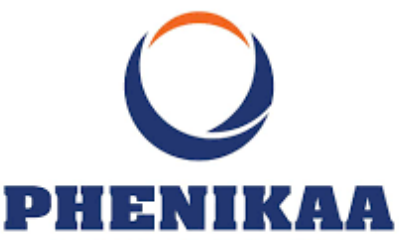 \\ UNIVERSITY
}

Hà Nội, ngày 4 tháng 1 năm 2021

http://isr.phenikaa-uni.edu.vn/chitiet/tin-tuc 2019222758 84/isr-phenikaa-uni-vuonlen-3-bang-repec-2020

Trung tâm ISR | Phenikaa Uni — Kết thúc năm 2020 đầy khó khăn giữa đại dịch COVID-19, bảng tổng sắp các đơn vị nghiên cứu kinh tế-quản trị RePEc/IDEAS đã cho biết dữ liệu kết thúc năm 2020.

Theo dữ liệu RePEc cho tới tháng kết thúc 2020, Việt Nam đã có 161 tác giả và 53 cơ quan nghiên cứu-đào tạo kinh tế-quản trị có đăng ký hồ sơ học thuật với RePEc.

Lần đầu tiên trong lịch sử tồn tại 41 tháng (kể từ 1-8-2017), Trung tâm ISR đã vươn lên vị trí \#3 của danh sách các đơn vị nghiên cứu Việt Nam trong RePEc.

(Đầu 2020, ISR vươn lên vị trí \#4 sau năm 2019 miệt mài cống hiến.) 


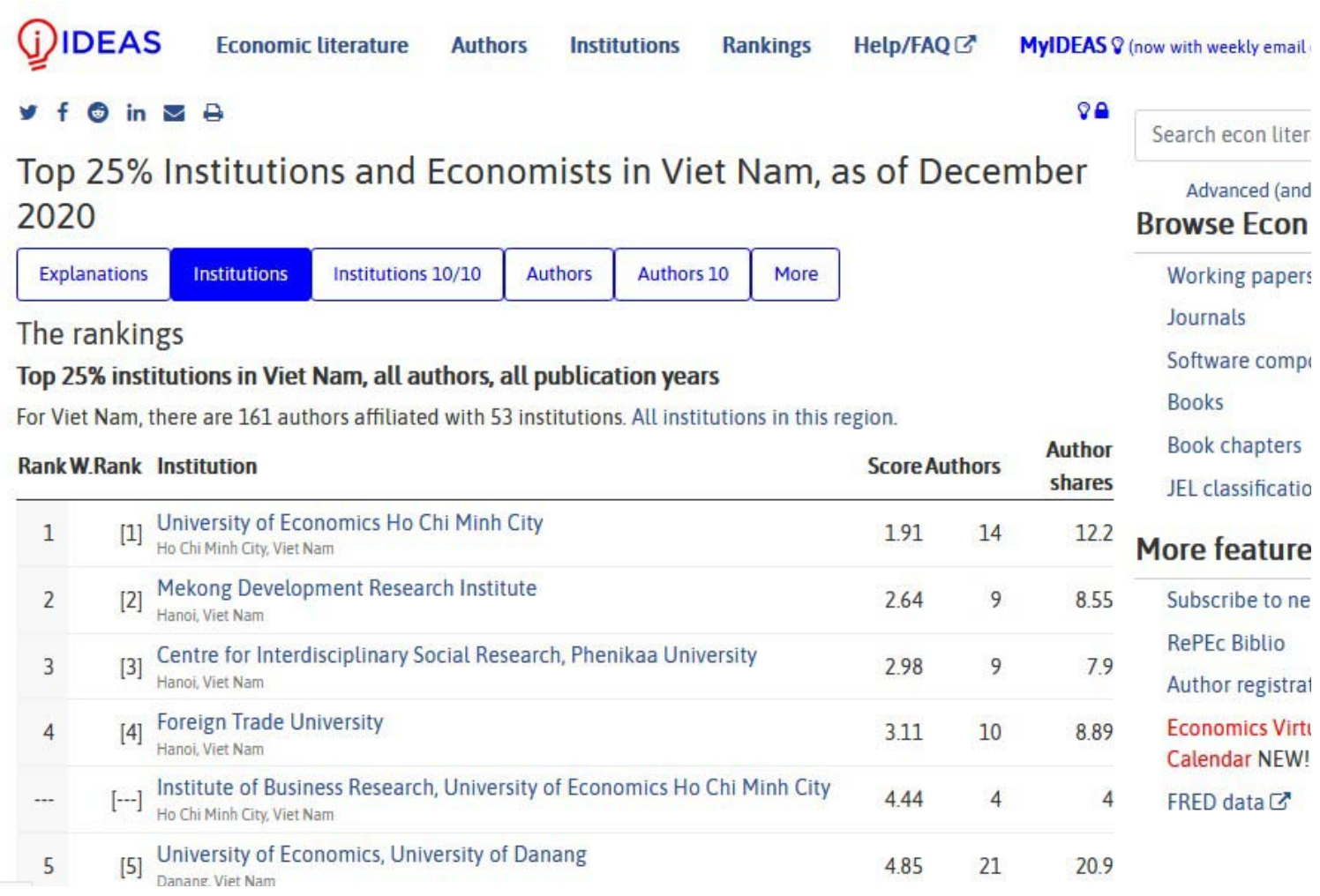

https://ideas.repec.org/top/top.vietnam.html

Đây là kết quả rất bất ngờ với toàn bộ Trung tâm ISR trong năm 2020. Lãnh đạo ISR đánh giá từ đầu năm, việc trụ lại trong Top 5 cũng là quá khó, với hàng chục trường đại học có khối ngành kinh tế-quản trị mạnh đang đẩy mạnh đầu tư hàng triệu đôla mỗi năm cho công việc nghiên cứu và xuất bản.

Trong khi đó ISR lại đi theo chính sách đầu tư chi phí tối thiểu [2] nhằm thúc đẩy hiệu năng kinh tế trên đồng vốn đầu tư theo luật Inada 1963[3], và có lượng nhân lực vô cùng bé nhỏ.

Hiện nay, Trung tâm ISR đã vượt lên trên Trường ĐH Ngoại thương (\#4) và dẫn trước khá xa các đơn vị mạnh (bao gồm cả quốc tế) như: Trường ĐH Kinh tế (thuộc ĐH Đà Nẵng), Trường Quản trị và Chính sách công ĐH Fulbright, Trường Kinh doanh và Quản trị RMIT Uni, và ĐH Kinh tế quốc dân.

Ngoài việc đã bố cáo vượt 100 ấn phẩm quốc tế sau 1249 ngày tồn tại[4], Trung tâm ISR đang củng cố truyền thống là nơi xuất bản những tác phẩm công phu, liên ngành, sử dụng kỹ thuật phân tích hiện đại nhất, và có tính nguyên tác cao.

Những tác phẩm này được kỳ vọng là hình ảnh "Đá vẫn trơ gan cùng tuế nguyệt" và cơ bản là các vấn đề có giá trị phổ quát, xuyên lịch sử, không có tuổi, và có khả năng tham chiếu đa văn hóa. Tiêu biểu nhất phải kể đến $[5,6,7]$. 


\section{Tài liệu tham khảo:}

[1] RePEc. (2021). Top 25\% Institutions and Economists in Viet Nam, as of December 2020. Retrieved from: https://ideas.repec.org/top/top.vietnam.html (accessed: Jan 4, 2021).

[2] Vuong QH. (2018). The (ir)rational consideration of the cost of science in transition economies. Nature Human Behaviour, 2(1), 5.

[3] Inada KI. (1963). On a two-sector model of economic growth: Comments and a generalization. The Review of Economic Studies, 30(2), 119-127.

[4] Nguyen TTH, Nguyen MH, Ho MT. (2021). Crossing the 100-publication milestone to celebrate the new year 2021. OSF Preprints (Jan. 1), DOI:10.31219/osf.io/tyqj5.

[5] Vuong QH, Bui QK, La VP, et al. (2018). Cultural additivity: behavioural insights from the interaction of Confucianism, Buddhism and Taoism in folktales. Palgrave Communications, 4(1), 143.

[6] Vuong QH, Bui QK, La VP, et al. (2019). Cultural evolution in Vietnam's early 20th century: A Bayesian networks analysis of Hanoi Franco-Chinese house designs. Social Sciences \& Humanities Open, 1(1), 100001.

[7] Vuong QH, Ho MT, Nguyen HKT, et al. (2020). On how religions could accidentally incite lies and violence: Folktales as a cultural transmitter. Palgrave Communications, 6(1), 82. 